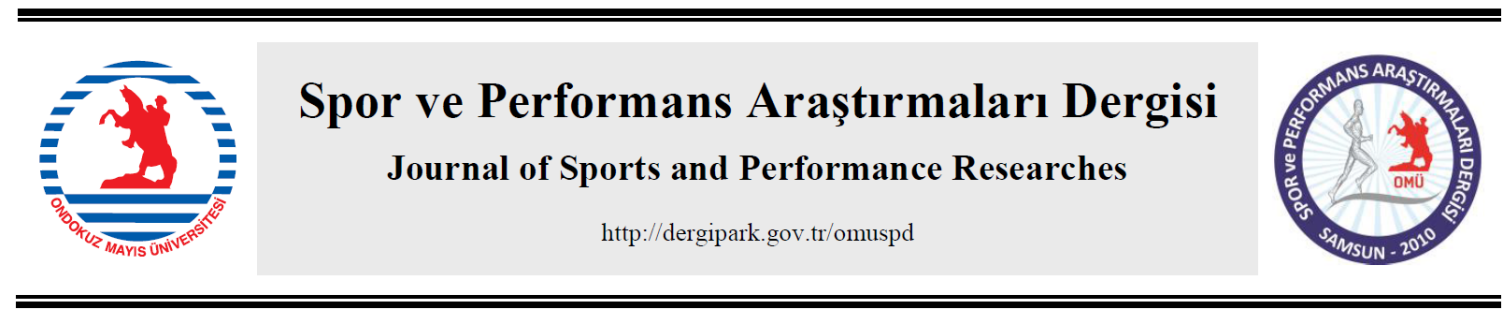

Geliş Tarihi/Received : 05.10.2015

Kabul Tarihi/Accepted :14.06.2017

DOI: $10.17155 / o m u s p d .322779$

\title{
GÜREŞ VE JUDO SPOR DALLARINDA GÖRÜLEN SPOR YARALANMALARININ KARŞILAŞTIRILMASI
}

\author{
Banu KABAK ${ }^{1}$ \\ Muharrem KARANFiLCi ${ }^{1}$ \\ Nuran KARAKUYU ${ }^{2}$
}

\section{ÖZET}

Bu çalışmanın amacı kullanılan kas grupları açısından benzer spor dalları olan judo ve güreşte, antrenmanda ve müsabakada meydana gelen yaralanmaları karşılaştırmaktır. Bu çalışmaya, Ocak 2011 ila Haziran 2011 arasında bölgesel ve ulusal müsabakalarda mücadele eden judocular ve güreşçiler katılmıştır. Araştırmaya 13-27 yaş aralığında olan judo (727) ve güreş (700) yapan toplam 1427 (300 kadın, 1127 erkek) sporcu gönüllü olarak katılmıştır. Sporculara, araştırmacılar tarafından hazırlanan konu ile ilgili 20 soruluk bir anket uygulanmıştır. Tüm sporcuların \% 23,4'ünde ( $n=159)$ müsabaka anında en yaygın spor sakatlığı kontüzyon-laserasyondur. Judo yapan sporcuların \%24,9'unda $(n=80)$ kontüzyon-laserasyon, güreş yapan sporcuların \%25,4'ünde ( $n=91$ ) en sık kırık görülmüştür. Her iki grupta da en fazla yaralanan vücut bölgesi el-el bileği, dirsek omuz bölgesi olarak tespit edilmiştir. Judo ve güreş spor dallarında benzer yaralanma türlerinin, benzer vücut bölgelerinde meydana geldiği tespit edilmiştir. Güreş ve judo gibi temas sporlarında görülen spor yaralanmalarının, değişik yaş kategorilerinde daha kapsamlı bir çalışma ile araştırılması önerilmektedir.

Anahtar Kelimeler: Güreş, Judo, Spor yaralanması

\section{A COMPARISON OF SPORTS INJURIES IN JUDO AND WRESTLING SPORTS}

\section{ABSTRACT}

The aim of this study is to compare sports injuries that occur during training and competitions of judo and wrestling sports which are similar sports in terms of the muscle groups used. This study was conducted with judo and wrestling athletes who participated in local and national competitions during a six month period between January and June in 2011. A total of 1427 athletes (300 women, 1127 men) between the ages of 13 and 27 who performed judo (727) and wrestling (700) participated voluntarily in the study. A questionnaire of 20 questions related with the subject was applied to athletes. During competitions, the most common sports injury was contusion laceration and occurred in $23.4 \%(n=159)$ of all athletes. The most frequent sports injuries were contusion laceration in $24.9 \%(n=80)$ of Judo athletes and fracture in $25,4 \%(n=91)$ of wrestlers. In both groups, the most frequently injured body regions were hand-wrist, elbow and shoulder. In wrestling and judo sports, types of similar sports injuries have been found to occur in similar body parts. It has been suggested that sports injuries in contact sports such as wrestling and judo should be investigated by a more comprehensive study in different age categories.

Keywords: Wrestling, Judo, Sports injury

\footnotetext{
${ }^{1}$ Gençlik ve Spor Bakanlığı Ankara. "Yazışmadan Sorumlu Yazar" denizemre35@hotmail.com

${ }^{2}$ Konya Numune Hastanesi Konya.
} 


\section{GiRiş}

Spor yaralanmaları terimi, vücudun tamamının ya da bir bölgesinin, normalden fazla bir kuvvetle karşılaşması sonucunda, dokuların dayanıklılık sınııının aşılmasıyla ortaya çıkan durumları kapsar. Spor yaralanmaları genel olarak sportif aktiviteler sırasında meydana gelen her türlü hasara verilen ortak bir isimdir [1]. Vücudumuzda fiziksel aktiviteler sonucu meydana gelen bu hasarlar birçok sebeple ortaya çıkabilmektedir. Bir spor sakatlığının ciddiyetinin yorumlanabilmesi için bazı faktörlerin detaylı olarak incelenmesi gerekmektedir. Bunlar; Yaralanmanın özelliği (çekme, zorlama, kopma, kontüzyon, çıkık, kırık, çatlak, açık yara, enfeksiyon, enflamasyon), tedavinin süresi ve özelliği, spora katılamama süresi, çalışma ve iş süresi kayıpları, kalıcı sakatık durumları ve direkt ve indirek maliyetler olarak sınıflandırılabilmektedir [2].

Spor yapanlarda yaralanmanın görülme olasılığı 4.000 kişide bir, ölüm oranı 40.000 kişide bir ve büyük bir kaza ile karşılaşma oranı ise 40 kişide bir olduğu bildirilmektedir. Bununla birlikte en sık yaralanmanın görüldüğü spor branşlarının \%10 ile futbol, \%6 ile güreş, \%3 ile hentbol ve boks, \%1 ile atletizm ve \%0,5 ile kayak olduğu saptanmıştır [3].

Güreş: rakip iki kişinin özel bir alanda ve belli bir sürede, herhangi bir malzeme ve araç kullanmadan belirli kurallar içerisinde tüm fizyolojik ve psikolojik güçlerini kullanarak birbirinin sırtını yere getirmek ve teknik üstünlük sağlamak için yaptığı mücadeledir [4]. Güreş yoğun bir güç gerektiren ve yaralanma riski yüksek sporlar arasında yer almaktadır [5]. Bir güreş müsabakasında güreşçi rakibini yenebilmek için vücudunun tüm parçalarını kullanmaktadır. Bu süreçte sporculara uygulanan bio-mekanik kuvvetler vücudun farklı bölgelerinde hasara neden olabilmektedir [6]. En sık görülen yaralanmalar burkulmalar, incinmeler ve çürüklerin olduğu bildirilmiştir [7].

Bazı açılardan güreşe benzeyen judo, eski bir Japon dövüşü olan jiujitsu'dan doğmuştur [8]. Judo sınırları belirlenmiş bir saha içerisinde ayakta yapılan belirli prensipleri olan bir dövüş sanatı, aynı zamanda olimpik bir spordur [9,10]. 1964 yılından beri (1964-TOKYO) olimpiyatlarda yer alan judo, pek çok ülkede yaygın bir spor dalıdır. Bunun yanında kendini savunma yöntemi olarak da öğrenilmektedir. Amaç rakibi, omuzdan ya da kalçadan savurmak, yerde hareketsiz bırakmak, kol eklemlerine ya da boynuna basınç uygulamak gibi tekniklerle yenmektir [8]. Judo da yarışma kategorileri, yaş, cinsiyet ve siklete göre belirlenmektedir [11]. 
Günümüzde judo dünya dövüş sporlarının en popülerleri arasında yer almaktadır [12]. Judo yaralanmalarının \%85'inin her iki sporcu da ayakta iken rakibe ilk atak sırasında uygulanan kavrama kuvvetinin etkisiyle ve rakip yere düştüğünde zeminle vücut ağırlığı arasındaki etkileşimden olduğu bildirilmektedir $[13,14]$. Ayrıca belirtilen kavrama durumunun ellerin ve parmakların yaralanmasına neden olduğu [14-16] fırlatılmaların da birkaçı şiddetli ve yıkıcı olmak üzere, vakaların \%70'inde yaralanmalara sebebiyet verdiği ileri sürülmektedir $[17,18]$.

Bu çalışma belirli yaşlardaki judo ve güreşçilerde antrenman ve müsabaka sırasında meydana gelen yaralanmaları karşılaştırma amacını taşımaktadır.

\section{MATERYAL ve METOT}

Bu çalışmaya Ocak-Haziran 2011 tarihleri arasında yapılan bölgesel ve ulusal müsabakalarda yarışan judocu ve güreşçiler katılmıştır. 13-27 yaş aralığında judo (727) ve güreş (700) yapan toplam 1427 (300 kadın, 1127 erkek) sporcu çalışmaya gönüllü olarak katılmıştır. Her müsabakadan sonra anketler sporculara yaptırılmış ve "Helsinki Deglerasyonu" gereğince bilgilendirilmişlerdir.

Sporculara konu ile ilgili araştırmacılar tarafından hazırlanan ve iki bölümden oluşan 20 soruluk anket dağıtılmıştır. Birinci bölümde bazı demografik özellikleri belirleyici sorulara yer verilirken, ikinci bölümde sporculara spor yaşamları boyunca yaralanma geçirip geçirmedikleri, geçirdikleri yaralanmalara verilen ad, yaralanmanın vücuttaki yeri, yaralanmanın ne zaman geçirildiği, yaralanma sonrasında görülen tedavi şekli ve spordan uzak kalma süreleri gibi sorulara yer verilmiştir. Çalışmada bir sporcunun birden fazla yaralanma geçirdiği göz önüne alınarak hesaplamalar yapılmıştır.

Çalışma sonucunda elde edilen veriler değerlendirilirken SPSS 22.0 for Windows (Chicago-USA) programı kullanılmıştır. Tanımlayıcı istatistiksel metotlar kategorik değişkenler için sayı ve yüzdeler şeklinde, sürekli değişkenler için ortalama \pm standart sapma şeklinde verilmiştir. Verilerin normal dağılıma uyumu Kolmogorov-Smirnov testi ile incelenmiş, iki grubun homojenliğine Levene's testi ile bakılmıştır. İki grup karşılaştırmasında veriler normal olmadığı için Mann Whitney-U testi uygulanmış, nominal değişkenler arasındaki ilişkilerin incelenmesinde ise Pearson Ki-kare testi kullanılmıştır. $\mathrm{P}<0,05$ düzeyi istatistiksel olarak anlamlı kabul ediliştir. 


\section{BULGULAR}

Toplam 1427 sporcunun \% 79'unun ( $n=1127)$ erkek, \% 21'inin ( $n=300)$ kadın olduğu ve \% 50,9'unun ( $n=727$ ) judo, \% 49,1'inin ( $n=700$ ) güreş branşına sahip olduğu görülmektedir.

Tablo 1. Sporcuların branş ve cinsiyete göre yaş ortalamaları

\begin{tabular}{llccccc}
\hline & Ortalama $\pm S S$ & Medyan & Minimum & Maksimum & IQR & P \\
\hline Judo (727) & $16,56 \pm 2,88$ & 16 & 13 & 27 & 3 & 0,00 \\
Güreş (700) & $15,82 \pm 2,30$ & 15 & 13 & 26 & 4 & 4 \\
\hline Erkek (1127) & $16,13 \pm 2,65$ & 16 & 13 & 27 & 27 & 2 \\
Kadın (300) & $16,44 \pm 2,60$ & 16 & 13 & 27 & \\
\hline
\end{tabular}

IQR: Çeyrekler arası aralık. SS: Standart sapma $\mathrm{P}<0,05$

Tablo 2. Branşa göre sporcuların yaş ortalamaları

\begin{tabular}{|c|c|c|c|c|c|c|c|}
\hline & & Ortalama $\pm S S$ & Medyan & Minimum & Maksimum & IQR & $P$ \\
\hline \multirow{3}{*}{ Judo } & Erkek (439) & $16,66 \pm 3,04$ & 16 & 13 & 27 & 3 & \multirow{3}{*}{0,26} \\
\hline & & & & & & & \\
\hline & Kadın (288 & $16,41 \pm 2,63$ & 16 & J & 21 & 2 & \\
\hline \multirow{2}{*}{ Güreş } & Erkek (688) & $15,80 \pm 2,30$ & 15 & 13 & 26 & 4 & \multirow{2}{*}{0,04} \\
\hline & Kadın (12) & $17,08 \pm 1,93$ & 17 & 15 & 21 & 3 & \\
\hline
\end{tabular}

Araştırmamıza katılan erkeklerin yaş ortalaması $16,13 \pm 2,65$, kadınların $16,44 \pm 2,60$ olarak bulunmuştur. Judo yapan sporcuların yaş ortalaması $16,56 \pm 2,88$ iken güreş yapanların $15,82 \pm 2,30$ olarak tespit edilmiştir. Güreşçilerin yaş ortalaması judoculara göre anlamlı olarak daha düşüktür $(P<0,05)$ (Tablo 1$)$. Judo yapan erkek sporcuların yaş ortalaması $16,66 \pm 3,04$,

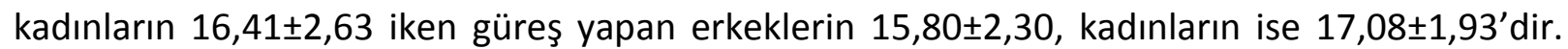
Güreş yapan kadın sporcuların yaş ortalamaları erkek güreşçilere göre anlamlı olarak daha yüksektir $(\mathrm{P}<0,05)$ (Tablo 2$)$.

Tablo 3. Sporcuların haftalık antrenman sıklığı

\begin{tabular}{|c|c|c|c|c|c|c|c|c|}
\hline & & & \multicolumn{4}{|c|}{ Antrenman Sıklığı } & \multirow{2}{*}{$\chi^{2}$} & \multirow[b]{2}{*}{$\mathrm{P}$} \\
\hline & & & 1-2 gün & 3-4 gün & 5-6 gün & Her gün & & \\
\hline \multirow[t]{4}{*}{ Branş } & Judo & $n$ & 15 & 159 & 284 & 269 & \multirow{6}{*}{19,42} & \multirow{6}{*}{0,00} \\
\hline & & $\%$ & 2,1 & 21,9 & 39,1 & 37,0 & & \\
\hline & Güreş & $\mathrm{n}$ & 7 & 98 & 288 & 307 & & \\
\hline & & $\%$ & 1,0 & 14,0 & 41,1 & 43,9 & & \\
\hline \multirow[t]{2}{*}{ Toplam } & & $n$ & 22 & 257 & 572 & 576 & & \\
\hline & & $\%$ & 1,5 & 18,0 & 40,1 & 40,4 & & \\
\hline
\end{tabular}

Araştırmamıza katılan sporcuların haftalık antrenman sıklığı verileri Tablo 3'te verilmiştir. Haftalık antrenman sıklığı dağılımı judocu ve güreşçiler arasında farklıdır $\left(\chi^{2}=19,42\right.$, $P<0,05)$. Judo yapan sporcuların \% 39,1'si ( $n=284)$ 5-6 gün antrenman yaparken güreş yapanların \% 43,9'u ( $n=307)$ her gün antrenman yapmaktadır. 
Tablo 4. Branşlara göre sporcuların antrenman süreleri

\begin{tabular}{|c|c|c|c|c|c|c|c|c|}
\hline & & & \multicolumn{4}{|c|}{ Antrenman Süresi } & \multirow[b]{2}{*}{$\chi^{2}$} & \multirow[b]{2}{*}{$\mathrm{P}$} \\
\hline & & & 1 saatten az & 1 saat & 1,5 saat & $\begin{array}{c}2 \text { saat ve daha } \\
\text { fazla }\end{array}$ & & \\
\hline \multirow{4}{*}{ Branş } & \multirow{2}{*}{ Judo } & $\mathrm{n}$ & 3 & 4 & 142 & 578 & \multirow{6}{*}{21,89} & \multirow{6}{*}{0,00} \\
\hline & & $\%$ & 0,4 & 0,6 & 19,5 & 79,5 & & \\
\hline & \multirow[b]{2}{*}{ Güreş } & $\mathrm{n}$ & 0 & 19 & 179 & 502 & & \\
\hline & & $\%$ & 0,00 & 2,7 & 25,6 & 71,7 & & \\
\hline \multirow{2}{*}{ Toplam } & & $\mathrm{n}$ & 3 & 23 & 321 & 1080 & & \\
\hline & & $\%$ & 0,2 & 1,6 & 22,5 & 75,7 & & \\
\hline
\end{tabular}

Günlük antrenman saatlerinin dağılımı judocu ve güreşçiler arasında aynı değildir $\left(\chi^{2}=\right.$ $21,89, P<0,05)$ (Tablo 4). Çalışmaya katılan sporcuların \% 75,7'si ( $n=1080$ ) günlük 2 saat ve daha fazla, \% 0,2'si (n=3) 1 saatten az antrenman yapmıştır. Judo yapan sporcuların $\% 79,5$ 'sinin ( $n=578)$ günlük 2 saat ve daha fazla, \% 0,4'ünün ( $n=3) 1$ saatten az antrenman yaptığı, güreş yapanların da \% 71,7'sinin (502) günlük 2 saat ve daha fazla antrenman yaptığı görülmektedir (Tablo 4).

Tablo 5. Sporcuların spora başlama yaşları

\begin{tabular}{|c|c|c|c|c|c|c|c|c|c|c|}
\hline & & & \multicolumn{5}{|c|}{ Spora Başlama Yaşı } & \multirow[b]{2}{*}{ Toplam } & \multirow[b]{2}{*}{$x^{2}$} & \multirow[b]{2}{*}{$\mathrm{P}$} \\
\hline & & & $\begin{array}{c}8 \text { yaş ve } \\
\text { altı }\end{array}$ & 9-11yaş & $12-14$ yaş & $15-17$ yaş & 18 ve üstü & & & \\
\hline \multirow{4}{*}{ Branş } & \multirow{2}{*}{ Judo } & $\mathrm{n}$ & 113 & 305 & 236 & 73 & 0 & 727 & \multirow{6}{*}{64,99} & \multirow{6}{*}{0,00} \\
\hline & & $\%$ & 15,5 & 42 & 32,5 & 10 & 0 & 100 & & \\
\hline & \multirow{2}{*}{ Güreş } & $\mathrm{n}$ & 53 & 266 & 350 & 30 & 1 & 700 & & \\
\hline & & $\%$ & 7,6 & 38 & 50 & 4,3 & 0,1 & 100 & & \\
\hline \multirow{2}{*}{ Toplam } & & $\mathrm{n}$ & 166 & 571 & 586 & 103 & 1 & 1427 & & \\
\hline & & $\%$ & 11,6 & 40 & 41,1 & 7,2 & 0,1 & 100 & & \\
\hline
\end{tabular}

Judocu ve güreşçiler arasında spora başlama yaş dağııımı farklıdır $\left(\chi^{2}=64,99, P=0,00\right)$ Sporcuların spora başlama yaşları incelendiğinde; güreşçilerin \%50'si ( $n=350)$ 12-14 yaşlarında, \%38'i ( $n=266$ ) 9-11 yaşlarında spora başlamışlardır. Judocular ise \%42'si ( $n=305)$ 9-11 yaşında, \%32,5’i ( $n=236)$ 12-14 yaşları arasında spora başlamışlardır (Tablo 5).

Tablo 6. Sporcuların bireysel antrenman durumları

\begin{tabular}{|c|c|c|c|c|c|c|}
\hline & & & \multicolumn{2}{|c|}{ Bireysel antrenman } & \multirow{2}{*}{$\chi^{2}$} & \multirow{2}{*}{$P$} \\
\hline & & & Evet & Hayır & & \\
\hline \multirow[t]{4}{*}{ Branş } & Judo & $\mathrm{n}$ & 521 & 206 & \multirow{6}{*}{47,73} & \multirow{6}{*}{0,00} \\
\hline & & $\%$ & 71,7 & 28,3 & & \\
\hline & Güreş & $\mathrm{n}$ & 606 & 94 & & \\
\hline & & $\%$ & 86,6 & 13,4 & & \\
\hline \multirow[t]{2}{*}{ Toplam } & & $\mathrm{n}$ & 1127 & 300 & & \\
\hline & & $\%$ & 79,0 & 21,0 & & \\
\hline
\end{tabular}


Tablo 6'da sporcuların bireysel antrenman yapıp yapmadıkları ile ilgili veriler verilmektedir. Bireysel antrenman yapma dağılımı judocu ve güreşçiler arasında farklıdır $\left(\chi^{2}=47,73, P=0,00\right)$. Katılımcıların \% 79'u ( $\left.n=1127\right)$ bireysel antrenman yaparken \% $21^{\prime}$ inin ( $n=300$ ) bireysel antrenman yapmadığı görülmektedir. Judocuların \% 71,7'si ( $n=521)$ bireysel antrenman yaparken güreşçilerin ise \% 86,6'sının $(n=606)$ bireysel antrenman yaptığı görülmektedir (Tablo 6).

Tablo 7. Branşlara göre müsabaka ve antrenman sırasında spor yaralanması geçirme durumu

\begin{tabular}{|c|c|c|c|c|c|c|c|}
\hline & & & \multicolumn{2}{|c|}{ Müsabakada Sakatlanma } & \multicolumn{2}{|c|}{ Antrenmanda Sakatlanma } & \multirow{2}{*}{ Toplam } \\
\hline & & & Evet & Hayır & Evet & Hayır & \\
\hline \multirow[t]{4}{*}{ Branş } & Judo & $\mathrm{n}$ & 232 & 495 & 241 & 486 & 727 \\
\hline & & $\%$ & 31,9 & 68,1 & 33,1 & 66,9 & 100,0 \\
\hline & Güreş & $\mathrm{n}$ & 270 & 430 & 243 & 457 & 700 \\
\hline & & $\%$ & 38,6 & 61,4 & 34,7 & 65,3 & 100,0 \\
\hline \multirow[t]{2}{*}{ Toplam } & & $\mathrm{n}$ & 502 & 925 & 484 & 943 & 1427 \\
\hline & & $\%$ & 35,2 & 64,8 & 33,9 & 66,1 & 100,0 \\
\hline
\end{tabular}

Sporcuların \% 35,2'si (n=502) müsabakada bir veya daha fazla spor yaralanması geçirdiğini bildirirken sporcuların \% 64,8'si (n=925) müsabaka anında herhangi bir spor yaralanması geçirmediğini, antrenmanlarda ise sporcuların \% 33,9'u ( $n=484$ ) bir veya daha fazla spor yaralanması geçirdiğini, \% 66,1'i ( $n=943$ ) herhangi bir spor yaralanması geçirmediğini belirtmişlerdir. Müsabaka anında judo yapanların \% 31,9'u (232) bir ya da daha fazla spor yaralanması geçirdiğini bildirirken, güreş yapanların \% 38,6'sı (n=270) spor yaralanması geçirdiğini ifade etmişlerdir. Antrenman anında ise judo yapanların \% 33,1'i (241) ve güreş yapanların \% 34,7'si $(n=243)$ bir ya da daha fazla spor yaralanması geçirdiğini bildirmişlerdir (Tablo 7).

Tablo 8. Yaş gruplarının spor dalına göre spor yaralanması geçirme oranları

\begin{tabular}{|c|c|c|c|c|c|c|c|c|c|c|}
\hline \multirow[b]{3}{*}{ Branş } & & & \multicolumn{4}{|c|}{ Müsabakada Sakatlanma } & \multicolumn{4}{|c|}{ Antrenmanda Sakatlanma } \\
\hline & & & \multicolumn{3}{|c|}{ Yaş Grubu } & \multirow{2}{*}{ Toplam } & \multicolumn{3}{|c|}{ Yaş Grubu } & \multirow{2}{*}{ Toplam } \\
\hline & & & $13-15$ & $16-18$ & $19-27$ & & $13-15$ & $16-18$ & $19-27$ & \\
\hline \multirow[t]{6}{*}{ Judo } & \multirow[t]{2}{*}{ Evet } & $\mathrm{n}$ & 56 & 107 & 69 & 232 & 69 & 112 & 60 & 241 \\
\hline & & $\%$ & 24,1 & 46,1 & 29,7 & 31,9 & 28,6 & 46,5 & 24,9 & 33,1 \\
\hline & \multirow[t]{2}{*}{ Hayır } & $\mathrm{n}$ & 206 & 236 & 53 & 495 & 193 & 231 & 62 & 486 \\
\hline & & $\%$ & 41,6 & 47,7 & 10,7 & 68,1 & 39,7 & 47,5 & 12,8 & 66,9 \\
\hline & \multirow{2}{*}{ Toplam } & $\mathrm{n}$ & 262 & 343 & 122 & 727 & 262 & 343 & 122 & 727 \\
\hline & & $\%$ & 36,0 & 47,2 & 16,8 & 100,0 & 36,0 & 47,2 & 16,8 & 100,0 \\
\hline \multirow[t]{6}{*}{ Güreş } & \multirow[t]{2}{*}{ Evet } & $\mathrm{n}$ & 137 & 86 & 47 & 270 & 109 & 82 & 52 & 243 \\
\hline & & $\%$ & 50,7 & 31,9 & 17,4 & 38,6 & 44,9 & 33,7 & 21,4 & 34,7 \\
\hline & \multirow[t]{2}{*}{ Hayır } & $\mathrm{n}$ & 247 & 130 & 53 & 430 & 275 & 134 & 48 & 457 \\
\hline & & $\%$ & 57,4 & 30,2 & 12,3 & 61,4 & 60,2 & 29,3 & 10,5 & 65,3 \\
\hline & \multirow{2}{*}{ Toplam } & $\mathrm{n}$ & 384 & 216 & 100 & 700 & 384 & 216 & 100 & 700 \\
\hline & & $\%$ & 54,9 & 30,9 & 14,3 & 100,0 & 54,9 & 30,9 & 14,3 & 100,0 \\
\hline \multirow[t]{6}{*}{ Toplam } & \multirow[t]{2}{*}{ Evet } & $\mathrm{n}$ & 193 & 193 & 116 & 502 & 178 & 194 & 112 & 484 \\
\hline & & $\%$ & 38,4 & 38,4 & 23,1 & 35,2 & 36,8 & 40,1 & 23,1 & 33,9 \\
\hline & \multirow[t]{2}{*}{ Hayır } & $\mathrm{n}$ & 453 & 366 & 106 & 925 & 468 & 365 & 110 & 943 \\
\hline & & $\%$ & 49,0 & 39,6 & 11,5 & 64,8 & 49,6 & 38,7 & 11,7 & 66,1 \\
\hline & \multirow{2}{*}{ Toplam } & $\mathrm{n}$ & 646 & 559 & 222 & 1427 & 646 & 559 & 222 & 1427 \\
\hline & & $\%$ & 45,3 & 39,2 & 15,6 & 100,0 & 45,3 & 39,2 & 15,6 & 100,0 \\
\hline
\end{tabular}


Müsabaka anında judo yapan sporcularda en fazla spor yaralanması geçiren yaş aralığı \% 46,1 ( $n=107)$ ile 16-18 yaş aralığı iken onu \% 29,7 ( $n=69)$ ile 19-27 yaş aralığı takip etmektedir. Güreş yapanlar da ise \% 50,7 ( $n=137)$ ile $13-15$ yaş aralığında en fazla iken onu \% $31,9(n=86)$ ile $16-18$ yaş aralığı izlemektedir. Antrenman anında judo yapanların spor sakatlığı geçirdiği yaş aralığı yine \% 46,5 (n=112) ile 16-18 yaş aralığında iken, güreşte \% 44,9 (n=109) ile 13-15 yaş aralığıdır (Tablo 8).

Tablo 9. Branşlara göre sporcuların müsabakada ve antrenmanda yaralanma geçirme sayısı

\begin{tabular}{|c|c|c|c|c|c|c|c|c|}
\hline & & & \multicolumn{3}{|c|}{ Müsabaka yaralanma sayısı } & \multicolumn{3}{|c|}{ Antrenman yaralanma sayısı } \\
\hline & & & \multicolumn{2}{|c|}{ Branş } & \multirow{2}{*}{ Toplam } & \multicolumn{2}{|c|}{ Branş } & \multirow{2}{*}{ Toplam } \\
\hline & & & Judo & Güreş & & Judo & Güreş & \\
\hline & \multirow[t]{2}{*}{0} & $n$ & 495 & 430 & 925 & 486 & 457 & 943 \\
\hline & & $\%$ & 68,1 & 61,4 & 64,8 & 66,9 & 65,3 & 66,1 \\
\hline & \multirow[t]{2}{*}{1} & $\mathrm{n}$ & 174 & 204 & 378 & 189 & 200 & 389 \\
\hline & & $\%$ & 23,9 & 29,1 & 26,5 & 26,0 & 28,6 & 27,3 \\
\hline & \multirow[t]{2}{*}{2} & $\mathrm{n}$ & 40 & 48 & 88 & 42 & 31 & 73 \\
\hline & & $\%$ & 5,5 & 6,9 & 6,2 & 5,8 & 4,4 & 5,1 \\
\hline & \multirow[t]{2}{*}{3} & $\mathrm{n}$ & 9 & 15 & 24 & 6 & 10 & 16 \\
\hline & & $\%$ & 1,2 & 2,1 & 1,7 & 0,8 & 1,4 & 1,1 \\
\hline & \multirow[t]{2}{*}{4} & $\mathrm{n}$ & 5 & 2 & 7 & 2 & 1 & 3 \\
\hline & & $\%$ & 0,7 & 0,3 & 0,5 & 0,3 & 0,1 & 0,2 \\
\hline & \multirow[t]{2}{*}{5} & $n$ & 4 & 1 & 5 & 2 & 0 & 2 \\
\hline & & $\%$ & 0,6 & 0,1 & 0,4 & 0,3 & 0,0 & 0,1 \\
\hline & \multirow[t]{2}{*}{6} & $n$ & 0 & 0 & 0 & 0 & 1 & 1 \\
\hline & & $\%$ & 0,0 & 0,0 & 0,0 & 0,0 & 0,1 & 0,1 \\
\hline \multirow[t]{2}{*}{ Toplam } & & $\mathrm{n}$ & 727 & 700 & 1427 & 727 & 700 & 1427 \\
\hline & & $\%$ & 100,0 & 100,0 & 100,0 & 100,0 & 100,0 & 100,0 \\
\hline
\end{tabular}

Araştırmada judo yapan sporcuların 495'sı $(\% 68,1)$ müsabaka sırasında hiç spor yaralanması geçirmemişken $174(\% 23,9)$ sporcu en az bir spor yaralanması geçirmiş ve 4 $(\% 0,6)$ sporcu ise beş kez spor yaralanması geçirmiştir. Güreş yapan sporcuların 430'u $(\% 61,4)$ müsabaka anında spor yaralanması geçirmediğini, $204(\%$ 29,1) sporcu en az bir kez spor yaralanması geçirdiğini ve $1(\% 0,4)$ sporcu 5 kez spor yaralanması geçirdiğini belirtmişlerdir. Judo yapan sporcuların 486'sı $(\% 66,9)$ antrenman sırasında hiç spor yaralanması geçirmemişken 189 (\% 26) sporcu en az bir spor yaralanması geçirmiş ve 2 (\% 0,3) sporcu ise beş kez spor yaralanması geçirmiştir. Güreş yapan sporcuların 457'sı (\% 65,3) antrenman anında spor yaralanması geçirmediğini, 200 (\% 28,6) sporcu en az bir kez spor yaralanması geçirdiğini ve $1(\% 0,1)$ sporcu 6 kez spor yaralanması geçirdiğini ifade etmişlerdir (Tablo 9). 
Tablo 10. Spor yaralanmalarının tedavi süreleri

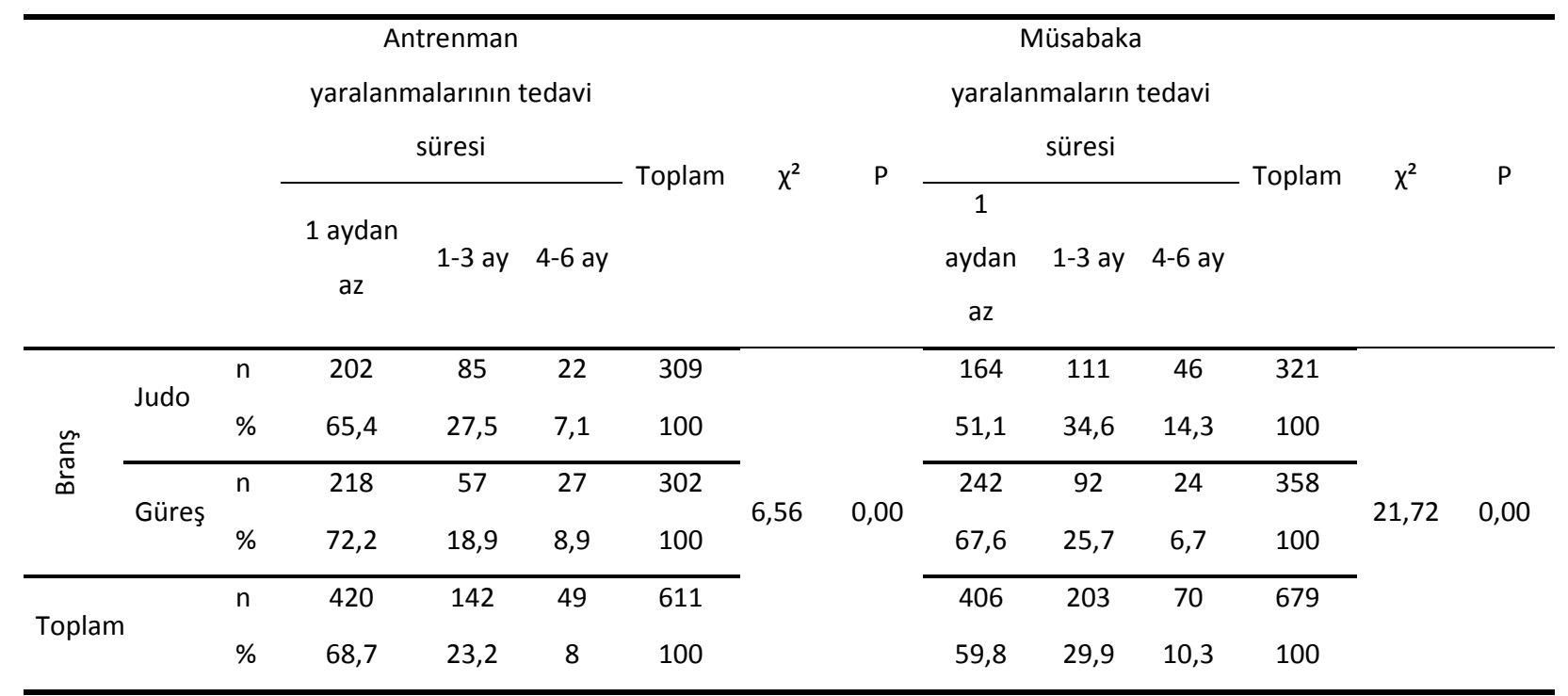

Veriler frekans ve yüzde olarak verildi. Değişkenlerin karşılaştırması Pearson Ki-kare testi

Hem müsabaka hem de antrenman sırasında geçirilen yaralanmaların tedavi sürelerinin dağılımının her iki branşta da farklı olduğu tespit edilmiştir (müsabaka: $X^{2}=21,72$, $P=0,00$; antrenman: $\left.X^{2}=6,56, P=0,00\right)$. Antrenman sırasında geçirilen spor yaralanmalarının tedavi süreleri değerlendirildiğinde judo yapanların \%65,4'ü (202) 1 aydan daha az bir sürede tedavi olurken güreş yapan sporcuların \%72,2'si (218) bir aydan daha kısa sürede tedavi olmuştur. Müsabaka anında da spor yaralanması geçirenlerin tedavi süreleri aynı şekilde judocuların \%51,1'i ( $n=164)$, güreşçilerin \% 67,6'sı (n=242) bir aydan daha az bir sürede tedavi olmuşlardır (Tablo 10). 
Banu KABAK Muharrem KARANFILCI Nuran KARAKUYU

Tablo 11. Judo ve Güreş Yapan Sporcuların Müsabaka Sırasında Geçirdikleri Yaralanmaların Türü ve Yaralanma Yeri Dağılımları

\begin{tabular}{|c|c|c|c|c|c|c|c|c|c|c|c|c|c|c|c|}
\hline \multirow[b]{2}{*}{ Branş } & & & & \multicolumn{11}{|c|}{ Müsabaka Sırasında Geçirilen Yaralanmalar } & \multirow[b]{2}{*}{ Toplam } \\
\hline & & & & $\begin{array}{l}\text { kontüzyon- } \\
\text { laserasyon }\end{array}$ & burkulma & kırık & çıkık & kopma & çekme & yırtık & tendinit & $\begin{array}{c}\text { omuz } \\
\text { sıkışma }\end{array}$ & $\begin{array}{c}\text { bel } \\
\text { problemleri }\end{array}$ & Diğer & \\
\hline \multirow{12}{*}{$\stackrel{\circ}{\circ}$} & \multirow{11}{*}{ 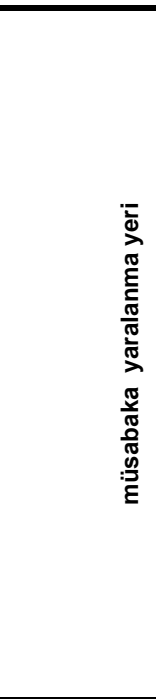 } & $\begin{array}{l}\text { Ayak- } \\
\text { ayakbileği }\end{array}$ & $\begin{array}{l}n \\
\%\end{array}$ & $\begin{array}{c}20 \\
23,5 \\
\end{array}$ & $\begin{array}{c}58 \\
68,2 \\
\end{array}$ & $\begin{array}{c}5 \\
5,9 \\
\end{array}$ & $\begin{array}{c}1 \\
1,2 \\
\end{array}$ & $\begin{array}{c}0 \\
0,0 \\
\end{array}$ & $\begin{array}{c}0 \\
0,0 \\
\end{array}$ & $\begin{array}{c}1 \\
1,2 \\
\end{array}$ & $\begin{array}{c}0 \\
0,0 \\
\end{array}$ & $\begin{array}{c}0 \\
0,0 \\
\end{array}$ & $\begin{array}{c}0 \\
0,0 \\
\end{array}$ & $\begin{array}{c}0 \\
0,0 \\
\end{array}$ & $\begin{array}{c}85 \\
26,5 \\
\end{array}$ \\
\hline & & Diz & $\begin{array}{l}\mathrm{n} \\
\%\end{array}$ & $\begin{array}{c}6 \\
14,0 \\
14,\end{array}$ & $\begin{array}{c}2 \\
4,7 \\
\end{array}$ & $\begin{array}{c}2 \\
4,7 \\
\end{array}$ & $\begin{array}{c}2 \\
4,7 \\
\end{array}$ & $\begin{array}{c}12 \\
27,9 \\
\end{array}$ & $\begin{array}{c}0 \\
0,0\end{array}$ & $\begin{array}{c}19 \\
44,2 \\
\end{array}$ & $\begin{array}{c}0 \\
0,0\end{array}$ & $\begin{array}{c}0 \\
0,0\end{array}$ & $\begin{array}{c}0 \\
0,0\end{array}$ & $\begin{array}{c}0 \\
0,0 \\
\end{array}$ & $\begin{array}{c}43 \\
13,4 \\
\end{array}$ \\
\hline & & El-el bileği & $\begin{array}{l}\mathrm{n} \\
\%\end{array}$ & $\begin{array}{c}12 \\
24,0\end{array}$ & $\begin{array}{c}7 \\
14,0 \\
\end{array}$ & $\begin{array}{c}16 \\
32,0 \\
\end{array}$ & $\begin{array}{c}9 \\
18,0 \\
\end{array}$ & $\begin{array}{c}2 \\
4,0\end{array}$ & $\begin{array}{c}0 \\
0,0\end{array}$ & $\begin{array}{c}0 \\
0,0 \\
\end{array}$ & $\begin{array}{c}2 \\
4,0 \\
\end{array}$ & $\begin{array}{c}0 \\
0,0\end{array}$ & $\begin{array}{c}0 \\
0,0\end{array}$ & $\begin{array}{c}2 \\
4,0 \\
\end{array}$ & $\begin{array}{c}50 \\
15,6 \\
\end{array}$ \\
\hline & & Dirsek & $\begin{array}{l}\mathrm{n} \\
\% \\
\end{array}$ & $\begin{array}{c}9 \\
40,9 \\
\end{array}$ & $\begin{array}{c}5 \\
22,7 \\
\end{array}$ & $\begin{array}{c}5 \\
22,7 \\
\end{array}$ & $\begin{array}{c}2 \\
9,1 \\
\end{array}$ & $\begin{array}{c}0 \\
0,0 \\
0,0\end{array}$ & $\begin{array}{c}0 \\
0,0 \\
0,0\end{array}$ & $\begin{array}{c}1 \\
4,5 \\
\end{array}$ & $\begin{array}{c}0 \\
0,0 \\
\end{array}$ & $\begin{array}{c}0 \\
0,0 \\
0,0\end{array}$ & $\begin{array}{c}0 \\
0,0 \\
\end{array}$ & $\begin{array}{c}0 \\
0,0 \\
\end{array}$ & $\begin{array}{l}22 \\
6,9 \\
\end{array}$ \\
\hline & & Omuz & $\begin{array}{l}\mathrm{n} \\
\% \\
\end{array}$ & $\begin{array}{c}19 \\
32,8 \\
\end{array}$ & $\begin{array}{c}0 \\
0,0 \\
\end{array}$ & $\begin{array}{c}1 \\
1,7 \\
\end{array}$ & $\begin{array}{c}18 \\
31,0 \\
\end{array}$ & $\begin{array}{c}4 \\
6,9 \\
\end{array}$ & $\begin{array}{c}0 \\
0,0 \\
\end{array}$ & $\begin{array}{c}11 \\
19,0 \\
\end{array}$ & $\begin{array}{c}0 \\
0,0 \\
\end{array}$ & $\begin{array}{c}5 \\
8,6 \\
\end{array}$ & $\begin{array}{c}0 \\
0,0 \\
\end{array}$ & $\begin{array}{c}0 \\
0,0 \\
\end{array}$ & $\begin{array}{c}58 \\
18,1 \\
\end{array}$ \\
\hline & & $\begin{array}{l}\text { Baldir- } \\
\text { uyluk }\end{array}$ & $\begin{array}{l}\mathrm{n} \\
\% \\
\end{array}$ & $\begin{array}{c}9 \\
26,5 \\
\end{array}$ & $\begin{array}{c}0 \\
0,0\end{array}$ & $\begin{array}{c}0 \\
0,0 \\
\end{array}$ & $\begin{array}{c}0 \\
0,0 \\
\end{array}$ & $\begin{array}{c}0 \\
0,0\end{array}$ & $\begin{array}{c}17 \\
50,0 \\
\end{array}$ & $\begin{array}{c}8 \\
23,5 \\
\end{array}$ & $\begin{array}{c}0 \\
0,0 \\
\end{array}$ & $\begin{array}{c}0 \\
0,0 \\
\end{array}$ & $\begin{array}{c}0 \\
0,0\end{array}$ & $\begin{array}{c}0 \\
0,0 \\
\end{array}$ & $\begin{array}{c}34 \\
10,6 \\
\end{array}$ \\
\hline & & Kalça & $\begin{array}{l}\mathrm{n} \\
\%\end{array}$ & $\begin{array}{c}0 \\
0,0\end{array}$ & $\begin{array}{c}0 \\
0,0\end{array}$ & $\begin{array}{c}2 \\
40,0 \\
\end{array}$ & $\begin{array}{c}0 \\
0,0 \\
\end{array}$ & $\begin{array}{c}0 \\
0,0\end{array}$ & $\begin{array}{c}3 \\
60,0 \\
\end{array}$ & $\begin{array}{c}0 \\
0,0 \\
\end{array}$ & $\begin{array}{c}0 \\
0,0 \\
\end{array}$ & $\begin{array}{c}0 \\
0,0 \\
\end{array}$ & $\begin{array}{c}0 \\
0,0 \\
\end{array}$ & $\begin{array}{c}0 \\
0,0 \\
\end{array}$ & $\begin{array}{c}5 \\
1,6 \\
\end{array}$ \\
\hline & & Bel & $\begin{array}{l}\mathrm{n} \\
\%\end{array}$ & $\begin{array}{c}0 \\
0,0 \\
\end{array}$ & $\begin{array}{c}0 \\
0,0 \\
0\end{array}$ & $\begin{array}{c}0 \\
0,0 \\
\end{array}$ & $\begin{array}{c}0 \\
0,0\end{array}$ & $\begin{array}{c}1 \\
20,0 \\
\end{array}$ & $\begin{array}{c}0 \\
0,0 \\
\end{array}$ & $\begin{array}{c}0 \\
0,0 \\
\end{array}$ & $\begin{array}{c}0 \\
0,0 \\
\end{array}$ & $\begin{array}{c}0 \\
0,0 \\
0\end{array}$ & $\begin{array}{c}4 \\
80,0 \\
\end{array}$ & $\begin{array}{c}0 \\
0,0 \\
\end{array}$ & $\begin{array}{c}5 \\
1,6 \\
\end{array}$ \\
\hline & & Göğüs & $\begin{array}{l}n \\
\%\end{array}$ & $\begin{array}{c}4 \\
44,4\end{array}$ & $\begin{array}{c}0 \\
0,0\end{array}$ & $\begin{array}{c}3 \\
33,3\end{array}$ & $\begin{array}{c}0 \\
0,0\end{array}$ & $\begin{array}{c}0 \\
0,0\end{array}$ & $\begin{array}{c}0 \\
0,0 \\
\end{array}$ & $\begin{array}{c}0 \\
0,0\end{array}$ & $\begin{array}{c}0 \\
0,0 \\
\end{array}$ & $\begin{array}{c}0 \\
0,0\end{array}$ & $\begin{array}{c}0 \\
0,0\end{array}$ & $\begin{array}{c}2 \\
22,2\end{array}$ & $\begin{array}{c}9 \\
2,8\end{array}$ \\
\hline & & Baş & $\begin{array}{l}\mathrm{n} \\
\%\end{array}$ & $\begin{array}{c}0 \\
0,0 \\
0,0\end{array}$ & $\begin{array}{c}0 \\
0,0 \\
\end{array}$ & $\begin{array}{c}1 \\
100,0 \\
\end{array}$ & $\begin{array}{c}0 \\
0,0 \\
\end{array}$ & $\begin{array}{c}0 \\
0,0 \\
0,0\end{array}$ & $\begin{array}{c}0 \\
0,0 \\
0,0\end{array}$ & $\begin{array}{c}0 \\
0,0 \\
\end{array}$ & $\begin{array}{c}0 \\
0,0 \\
0,0\end{array}$ & $\begin{array}{c}0 \\
0,0 \\
\end{array}$ & $\begin{array}{c}0 \\
0,0 \\
\end{array}$ & $\begin{array}{c}0 \\
0,0 \\
\end{array}$ & $\begin{array}{c}1 \\
0,3 \\
\end{array}$ \\
\hline & & Diğer & $\begin{array}{l}\mathrm{n} \\
\% \\
\end{array}$ & $\begin{array}{c}1 \\
11,1 \\
\end{array}$ & $\begin{array}{c}0 \\
0,0 \\
\end{array}$ & $\begin{array}{c}4 \\
44,4 \\
\end{array}$ & $\begin{array}{c}0 \\
0,0 \\
\end{array}$ & $\begin{array}{c}2 \\
22,2 \\
\end{array}$ & $\begin{array}{c}0 \\
0,0\end{array}$ & $\begin{array}{c}0 \\
0,0 \\
\end{array}$ & $\begin{array}{c}0 \\
0,0 \\
\end{array}$ & $\begin{array}{c}0 \\
0,0 \\
\end{array}$ & $\begin{array}{c}0 \\
0,0 \\
\end{array}$ & $\begin{array}{c}2 \\
22,2 \\
\end{array}$ & $\begin{array}{c}9 \\
2,8 \\
\end{array}$ \\
\hline & Toplam & & $\begin{array}{l}\mathrm{n} \\
\%\end{array}$ & $\begin{array}{c}80 \\
24,9 \\
\end{array}$ & $\begin{array}{c}72 \\
22,4 \\
\end{array}$ & $\begin{array}{c}39 \\
12,1 \\
\end{array}$ & $\begin{array}{c}32 \\
10,0 \\
\end{array}$ & $\begin{array}{l}21 \\
6,5 \\
\end{array}$ & $\begin{array}{l}20 \\
6,2 \\
\end{array}$ & $\begin{array}{c}40 \\
12,5 \\
\end{array}$ & $\begin{array}{l}2 \\
, 6 \\
\end{array}$ & $\begin{array}{c}5 \\
1,6 \\
\end{array}$ & $\begin{array}{c}4 \\
1,2 \\
\end{array}$ & $\begin{array}{c}6 \\
1,9 \\
\end{array}$ & $\begin{array}{c}321 \\
100,0 \\
\end{array}$ \\
\hline \multirow{11}{*}{ : } & \multirow{10}{*}{ 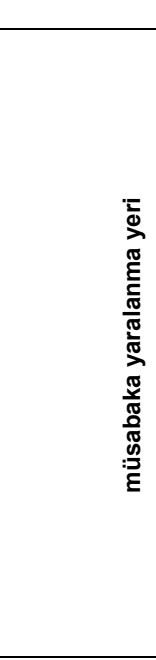 } & $\begin{array}{l}\text { Ayak-ayak } \\
\text { bileği }\end{array}$ & $\begin{array}{l}\mathrm{n} \\
\%\end{array}$ & $\begin{array}{c}5 \\
5,9\end{array}$ & $\begin{array}{c}62 \\
72,9\end{array}$ & $\begin{array}{c}17 \\
20,0\end{array}$ & $\begin{array}{c}1 \\
1,2\end{array}$ & $\begin{array}{c}0 \\
0,0\end{array}$ & $\begin{array}{c}0 \\
0,0\end{array}$ & $\begin{array}{c}0 \\
0,0\end{array}$ & $\begin{array}{c}0 \\
0,0\end{array}$ & $\begin{array}{c}0 \\
0,0\end{array}$ & $\begin{array}{c}0 \\
0,0\end{array}$ & $\begin{array}{c}0 \\
0,0\end{array}$ & $\begin{array}{c}85 \\
23,7\end{array}$ \\
\hline & & Diz & $\begin{array}{l}\mathrm{n} \\
\%\end{array}$ & $\begin{array}{c}11 \\
36,7\end{array}$ & $\begin{array}{c}4 \\
13,3\end{array}$ & $\begin{array}{c}1 \\
3,3\end{array}$ & $\begin{array}{c}0 \\
0,0\end{array}$ & $\begin{array}{c}2 \\
6,7\end{array}$ & $\begin{array}{c}0 \\
0,0\end{array}$ & $\begin{array}{c}11 \\
36,7\end{array}$ & $\begin{array}{c}0 \\
0,0\end{array}$ & $\begin{array}{c}0 \\
0,0\end{array}$ & $\begin{array}{c}0 \\
0,0\end{array}$ & $\begin{array}{c}1 \\
3,3\end{array}$ & $\begin{array}{l}30 \\
8,4\end{array}$ \\
\hline & & El-el bileği & $\begin{array}{l}\mathrm{n} \\
\%\end{array}$ & $\begin{array}{c}26 \\
26,3 \\
\end{array}$ & $\begin{array}{c}5 \\
5,1 \\
\end{array}$ & $\begin{array}{c}44 \\
44,4 \\
\end{array}$ & $\begin{array}{c}20 \\
20,2 \\
\end{array}$ & $\begin{array}{c}1 \\
1,0\end{array}$ & $\begin{array}{c}0 \\
0,0\end{array}$ & $\begin{array}{c}0 \\
0,0\end{array}$ & $\begin{array}{c}0 \\
0,0\end{array}$ & $\begin{array}{c}0 \\
0,0 \\
\end{array}$ & $\begin{array}{c}0 \\
0,0 \\
\end{array}$ & $\begin{array}{c}3 \\
3,0 \\
\end{array}$ & $\begin{array}{c}99 \\
27,7 \\
\end{array}$ \\
\hline & & Dirsek & $\begin{array}{l}\mathrm{n} \\
\% \\
\end{array}$ & $\begin{array}{c}2 \\
7,7 \\
\end{array}$ & $\begin{array}{c}0 \\
0,0\end{array}$ & $\begin{array}{c}13 \\
50,0 \\
\end{array}$ & $\begin{array}{c}7 \\
26,9\end{array}$ & $\begin{array}{c}0 \\
0,0 \\
\end{array}$ & $\begin{array}{c}0 \\
0,0 \\
\end{array}$ & $\begin{array}{c}0 \\
0,0 \\
\end{array}$ & $\begin{array}{c}0 \\
0,0 \\
\end{array}$ & $\begin{array}{c}0 \\
0,0\end{array}$ & $\begin{array}{c}0 \\
0,0\end{array}$ & $\begin{array}{c}4 \\
15,4 \\
\end{array}$ & $\begin{array}{l}26 \\
7,3 \\
\end{array}$ \\
\hline & & Omuz & $\begin{array}{l}n \\
\% \\
\end{array}$ & $\begin{array}{c}14 \\
28,6 \\
\end{array}$ & $\begin{array}{c}0 \\
0,0 \\
\end{array}$ & $\begin{array}{c}3 \\
6,1 \\
\end{array}$ & $\begin{array}{c}19 \\
38,8 \\
\end{array}$ & $\begin{array}{c}0 \\
0,0 \\
0,0\end{array}$ & $\begin{array}{c}2 \\
4,1 \\
\end{array}$ & $\begin{array}{r}11 \\
22,4 \\
\end{array}$ & $\begin{array}{c}0 \\
0,0 \\
\end{array}$ & $\begin{array}{c}0 \\
0,0 \\
\end{array}$ & $\begin{array}{c}0 \\
0,0 \\
\end{array}$ & $\begin{array}{c}0 \\
0,0 \\
\end{array}$ & $\begin{array}{c}49 \\
13,7 \\
\end{array}$ \\
\hline & & $\begin{array}{l}\text { Baldır- } \\
\text { uyluk }\end{array}$ & $\begin{array}{l}\mathrm{n} \\
\%\end{array}$ & $\begin{array}{c}6 \\
19,4 \\
\end{array}$ & $\begin{array}{c}0 \\
0,0 \\
\end{array}$ & $\begin{array}{c}0 \\
0,0 \\
\end{array}$ & $\begin{array}{c}0 \\
0,0 \\
\end{array}$ & $\begin{array}{c}0 \\
0,0 \\
\end{array}$ & $\begin{array}{c}12 \\
38,7 \\
\end{array}$ & $\begin{array}{c}11 \\
35,5 \\
\end{array}$ & $\begin{array}{c}2 \\
6,5 \\
\end{array}$ & $\begin{array}{c}0 \\
0,0 \\
\end{array}$ & $\begin{array}{c}0 \\
0,0 \\
\end{array}$ & $\begin{array}{c}0 \\
0,0 \\
\end{array}$ & $\begin{array}{l}31 \\
8,7 \\
\end{array}$ \\
\hline & & Kalça & $\begin{array}{l}\mathrm{n} \\
\%\end{array}$ & $\begin{array}{c}0 \\
0,0\end{array}$ & $\begin{array}{c}0 \\
0,0\end{array}$ & $\begin{array}{c}1 \\
50,0 \\
\end{array}$ & $\begin{array}{c}0 \\
0,0 \\
\end{array}$ & $\begin{array}{c}0 \\
0,0\end{array}$ & $\begin{array}{c}0 \\
0,0\end{array}$ & $\begin{array}{c}1 \\
50,0 \\
\end{array}$ & $\begin{array}{c}0 \\
0,0 \\
\end{array}$ & $\begin{array}{c}0 \\
0,0 \\
\end{array}$ & $\begin{array}{c}0 \\
0,0 \\
\end{array}$ & $\begin{array}{c}0 \\
0,0 \\
\end{array}$ & $\begin{array}{c}2 \\
06 \\
\end{array}$ \\
\hline & & Bel & $\begin{array}{l}\mathrm{n} \\
\% \\
\end{array}$ & $\begin{array}{c}7 \\
53,8 \\
\end{array}$ & $\begin{array}{c}0 \\
0,0 \\
\end{array}$ & $\begin{array}{c}0 \\
0,0 \\
\end{array}$ & $\begin{array}{c}0 \\
0,0 \\
\end{array}$ & $\begin{array}{c}0 \\
0,0 \\
\end{array}$ & $\begin{array}{c}0 \\
0,0 \\
\end{array}$ & $\begin{array}{c}0 \\
0,0 \\
\end{array}$ & $\begin{array}{c}0 \\
0,0 \\
\end{array}$ & $\begin{array}{c}0 \\
0,0 \\
\end{array}$ & $\begin{array}{c}5 \\
38,5 \\
\end{array}$ & $\begin{array}{c}1 \\
7,7 \\
\end{array}$ & $\begin{array}{r}13 \\
3,6 \\
\end{array}$ \\
\hline & & Göğüs & $\begin{array}{l}\mathrm{n} \\
\% \\
\end{array}$ & $\begin{array}{c}8 \\
47,1 \\
\end{array}$ & $\begin{array}{c}0 \\
0,0 \\
\end{array}$ & $\begin{array}{c}8 \\
47,1 \\
\end{array}$ & $\begin{array}{c}0 \\
0,0 \\
\end{array}$ & $\begin{array}{c}0 \\
0,0 \\
\end{array}$ & $\begin{array}{c}0 \\
0,0 \\
\end{array}$ & $\begin{array}{c}0 \\
0,0 \\
\end{array}$ & $\begin{array}{c}0 \\
0,0 \\
\end{array}$ & $\begin{array}{c}0 \\
0,0 \\
\end{array}$ & $\begin{array}{c}0 \\
0,0 \\
\end{array}$ & $\begin{array}{c}1 \\
5,9 \\
\end{array}$ & $\begin{array}{l}17 \\
4,7 \\
\end{array}$ \\
\hline & & Baş & $\begin{array}{l}n \\
\% \\
\end{array}$ & $\begin{array}{c}0 \\
0,0\end{array}$ & $\begin{array}{c}0 \\
0,0\end{array}$ & $\begin{array}{c}4 \\
66,7 \\
\end{array}$ & $\begin{array}{c}0 \\
0,0\end{array}$ & $\begin{array}{c}0 \\
0,0\end{array}$ & $\begin{array}{c}0 \\
0,0\end{array}$ & $\begin{array}{c}0 \\
0,0 \\
\end{array}$ & $\begin{array}{c}0 \\
0,0\end{array}$ & $\begin{array}{c}0 \\
0,0\end{array}$ & $\begin{array}{c}0 \\
0,0 \\
\end{array}$ & $\begin{array}{c}2 \\
33,3\end{array}$ & $\begin{array}{c}6 \\
1,7 \\
\end{array}$ \\
\hline & Toplam & & $\begin{array}{l}\mathrm{n} \\
\%\end{array}$ & $\begin{array}{c}79 \\
22,1\end{array}$ & $\begin{array}{c}71 \\
19,8\end{array}$ & $\begin{array}{c}91 \\
25,4\end{array}$ & $\begin{array}{c}47 \\
13,1\end{array}$ & $\begin{array}{c}3 \\
0,8\end{array}$ & $\begin{array}{l}14 \\
3,9\end{array}$ & $\begin{array}{l}34 \\
9,5\end{array}$ & $\begin{array}{c}2 \\
0,6\end{array}$ & $\begin{array}{c}0 \\
0,0\end{array}$ & $\begin{array}{c}0 \\
0,0\end{array}$ & $\begin{array}{c}12 \\
3,4\end{array}$ & $\begin{array}{c}358 \\
100,0\end{array}$ \\
\hline
\end{tabular}


Tablo 11 (Devam). Judo ve Güreş Yapan Sporcuların Müsabaka Sırasında Geçirdikleri Yaralanmaların Türü ve Yaralanma Yeri Dağılımları

\begin{tabular}{|c|c|c|c|c|c|c|c|c|c|c|c|c|c|c|c|}
\hline \multirow[b]{2}{*}{ Branş } & & & & & & & & üsabaka & da Geçir & ralanm & & & & & \\
\hline & & & & $\begin{array}{l}\text { kontüzyon- } \\
\text { laserasyon }\end{array}$ & burkulma & kırık & çıkık & kopma & çekme & yirtık & tendinit & $\begin{array}{c}\text { ommuz } \\
\text { sikışma }\end{array}$ & $\begin{array}{c}\text { bel } \\
\text { problemleri }\end{array}$ & Diğer & Toplam \\
\hline \multirow{24}{*}{$\begin{array}{l}\frac{E}{6} \\
\frac{0}{0} \\
\stackrel{0}{\circ}\end{array}$} & \multirow{22}{*}{ 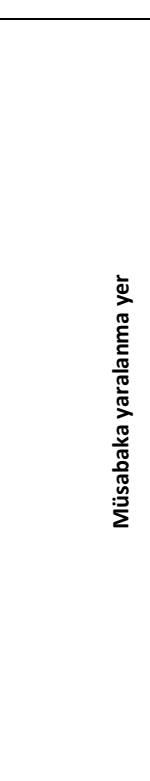 } & \multirow{2}{*}{$\begin{array}{l}\text { Ayak- } \\
\text { ayakbileği }\end{array}$} & $\mathrm{n}$ & 25 & 120 & 22 & 2 & 0 & 0 & 1 & 0 & 0 & 0 & 0 & 170 \\
\hline & & & $\%$ & 14,7 & 70,6 & 12,9 & 1,2 & 0,0 & 0,0 & 0,6 & 0,0 & 0,0 & 0,0 & 0,0 & 25,0 \\
\hline & & \multirow[t]{2}{*}{ Diz } & $n$ & 17 & 6 & 3 & 2 & 14 & 0 & 30 & 0 & 0 & 0 & 1 & 73 \\
\hline & & & $\%$ & 23,3 & 8,2 & 4,1 & 2,7 & 19,2 & 0,0 & 41,1 & 0,0 & 0,0 & 0,0 & 1,4 & 10,8 \\
\hline & & \multirow[t]{2}{*}{ El-el bileği } & $n$ & 38 & 12 & 60 & 29 & 3 & 0 & 0 & 2 & 0 & 0 & 5 & 149 \\
\hline & & & $\%$ & 25,5 & 8,1 & 40,3 & 19,5 & 2,0 & 0,0 & 0,0 & 1,3 & 0,0 & 0,0 & 3,4 & 21,9 \\
\hline & & \multirow[t]{2}{*}{ Dirsek } & $n$ & 11 & 5 & 18 & 9 & 0 & 0 & 1 & 0 & 0 & 0 & 4 & 48 \\
\hline & & & $\%$ & 22,9 & 10,4 & 37,5 & 18,8 & 0,0 & 0,0 & 2,1 & 0,0 & 0,0 & 0,0 & 8,3 & 7,1 \\
\hline & & \multirow[t]{2}{*}{ Omuz } & $n$ & 33 & 0 & 4 & 37 & 4 & 2 & 22 & 0 & 5 & 0 & 0 & 107 \\
\hline & & & $\%$ & 30,8 & 0,0 & 3,7 & 34,6 & 3,7 & 1,9 & 20,6 & 0,0 & 4,7 & 0,0 & 0,0 & 15,8 \\
\hline & & \multirow[t]{2}{*}{ Baldır-uyluk } & $n$ & 15 & 0 & 0 & 0 & 0 & 29 & 19 & 2 & 0 & 0 & 0 & 65 \\
\hline & & & $\%$ & 23,1 & 0,0 & 0,0 & 0,0 & 0,0 & 44,6 & 29,2 & 3,1 & 0,0 & 0,0 & 0,0 & 9,6 \\
\hline & & \multirow[t]{2}{*}{ Kalça } & $\mathrm{n}$ & 0 & 0 & 3 & 0 & 0 & 3 & 1 & 0 & 0 & 0 & 0 & 7 \\
\hline & & & $\%$ & 0,0 & 0,0 & 42,9 & 0,0 & 0,0 & 42,9 & 14,3 & 0,0 & 0,0 & 0,0 & 0,0 & 1,0 \\
\hline & & \multirow[t]{2}{*}{ Bel } & $\mathrm{n}$ & 7 & 0 & 0 & 0 & 1 & 0 & 0 & 0 & 0 & 9 & 1 & 18 \\
\hline & & & $\%$ & 38,9 & 0,0 & 0,0 & 0,0 & 5,6 & 0,0 & 0,0 & 0,0 & 0,0 & 50,0 & 5,6 & 2,7 \\
\hline & & \multirow[t]{2}{*}{ Göğüs } & $n$ & 12 & 0 & 11 & 0 & 0 & 0 & 0 & 0 & 0 & 0 & 3 & 26 \\
\hline & & & $\%$ & 46,2 & 0,0 & 42,3 & 0,0 & 0,0 & 0,0 & 0,0 & 0,0 & 0,0 & 0,0 & 11,5 & 3,8 \\
\hline & & \multirow[t]{2}{*}{ Baş } & $n$ & 0 & 0 & 5 & 0 & 0 & 0 & 0 & 0 & 0 & 0 & 2 & 7 \\
\hline & & & $\%$ & 0,0 & 0,0 & 71,4 & 0,0 & 0,0 & 0,0 & 0,0 & 0,0 & 0,0 & 0,0 & 28,6 & 1,0 \\
\hline & & \multirow[t]{2}{*}{ Diğer } & $\mathrm{n}$ & 1 & 0 & 4 & 0 & 2 & 0 & 0 & 0 & 0 & 0 & 2 & 9 \\
\hline & & & $\%$ & 11,1 & 0,0 & 44,4 & 0,0 & 22,2 & 0,0 & 0,0 & 0,0 & 0,0 & 0,0 & 22,2 & 1,3 \\
\hline & \multirow[t]{2}{*}{ Toplam } & & $n$ & 159 & 143 & 130 & 79 & 24 & 34 & 74 & 4 & 5 & 9 & 18 & 679 \\
\hline & & & $\%$ & 23,4 & 21,1 & 19,1 & 11,6 & 3,5 & 5,0 & 10,9 & 0,6 & 0,7 & 1,3 & 2,7 & 100,0 \\
\hline
\end{tabular}

Tüm sporcuların \% 23,4'ün ( $n=159)$ müsabaka anında geçirdiği spor yaralanması kontüzyon-laserasyondu. Tüm sporcuların \% 25 'in ( $n=170)$ müsabaka sırasında geçirdiği sakatlığın yeri ayak-ayak bileğinde görülmüştür. Judo yapan sporcuların \% 24,9'ünde (n=80) kontüzyonlaserasyon ve \%22,4'ünde ( $n=72)$ burkulma görüldü. Yine judo yapan sporcuların müsabaka anında geçirilen en sık yaralanma yerleri sırasıyla $\% 26,5^{\prime}$ in $(n=85)$ ayak-ayak bileği, \%18,1'i $(n=58)$ omuz, \%15,6'sı $(n=50)$ el-el bileği ve \%13,4'ü (n=43) dizdir. Güreş yapan sporcuların müsabaka anında en sık sırasıyla \% 25,4'ün ( $n=91)$ kırık, \%22,1'inde ( $n=79)$ kontüzyon-laserasyon, \%19,8'inde ( $n=71)$ burkulma görüldü. Güreş yapan katılımcıların müsabaka anında geçirdikleri en sık yaralanma yerleri sırasıyla \%27,7'si (n=99) el-el bileği, \%23,7'si (n=85) ayak-ayak bileği, $\% 13,7^{\prime}$ si ( $\left.n=49\right)$ omuz ve \%8,4'ü ( $\left.n=30\right)$ dizdir (Tablo.11). 
Banu KABAK

Muharrem KARANFILCI Nuran KARAKUYU

Tablo 12. Judo ve Güreş Yapan Sporcuların Antrenmanda Geçirdikleri Yaralanmaların Türü ve Yaralanma Yeri Dağılımlar

\begin{tabular}{|c|c|c|c|c|c|c|c|c|c|c|c|c|c|c|c|}
\hline & & & & $\begin{array}{l}\text { Kondüzyon- } \\
\text { laserasyon }\end{array}$ & Burkulma & Kırık & Çıkık & Kopma & Çekme & Yirtik0 & Tendinit & Sııışma & $\begin{array}{c}\text { Fitı-paraverteb } \\
\text { spazm }\end{array}$ & Diğer & \\
\hline \multirow{24}{*}{$\frac{}{\frac{0}{3}}$} & \multirow{22}{*}{ 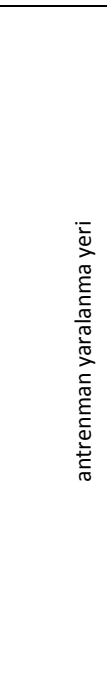 } & Ayak-ayak & $\mathrm{n}$ & 16 & 88 & 13 & 2 & 6 & 0 & 0 & 0 & 0 & 0 & 0 & 125 \\
\hline & & bileği & $\%$ & 12,8 & 70,4 & 10,4 & 1,6 & 4,8 & 0,0 & 0,0 & 0,0 & 0,0 & 0,0 & 0,0 & 40,5 \\
\hline & & Diz & $\mathrm{n}$ & 5 & 2 & 0 & 3 & 1 & 0 & 10 & 0 & 0 & 0 & 0 & 21 \\
\hline & & & $\%$ & 23,8 & 9,5 & 0,0 & 14,3 & 4,8 & 0,0 & 47,6 & 0,0 & 0,0 & 0,0 & 0,0 & 6,8 \\
\hline & & El-el bileği & $\mathrm{n}$ & 6 & 10 & 14 & 17 & 0 & 0 & 0 & 4 & 0 & 2 & 2 & 55 \\
\hline & & & $\%$ & 10,9 & 18,2 & 25,5 & 30,9 & 0,0 & 0,0 & 0,0 & 7,3 & 0,0 & 3,6 & 3,6 & 17,8 \\
\hline & & Dirsek & $n$ & 4 & 1 & 7 & 4 & 0 & 0 & 0 & 0 & 0 & 0 & 0 & 16 \\
\hline & & & $\%$ & 25,0 & 6,3 & 43,8 & 25,0 & 0 & 0,0 & 0,0 & 0,0 & 0,0 & 0,0 & 0,0 & 5,2 \\
\hline & & Omuz & $n$ & 25 & 0 & 0 & 13 & 0,0 & 0 & 4 & 0 & 2 & 0 & 0 & 44 \\
\hline & & & $\%$ & 56,8 & 0,0 & 0,0 & 29,5 & 0 & 0,0 & 9,1 & 0,0 & 4,5 & 0,0 & 0,0 & 14,2 \\
\hline & & Baldır-uyluk & $\mathrm{n}$ & 7 & 0 & 0 & 0 & 0,0 & 19 & 0 & 0 & 0 & 0 & 0 & 26 \\
\hline & & & $\%$ & 26,9 & 0,0 & 0,0 & 0,0 & 0 & 73,1 & 0,0 & 0,0 & 0,0 & 0,0 & 0,0 & 8,4 \\
\hline & & Bel & $n$ & 3 & 0 & 0 & 0 & 0,0 & 0 & 0 & 0 & 0 & 4 & 0 & 7 \\
\hline & & & $\%$ & 42,9 & 0,0 & 0,0 & 0,0 & 0 & 0,0 & 0,0 & 0,0 & 0,0 & 57,1 & 0,0 & 2,3 \\
\hline & & Kalça & $n$ & 1 & 0 & 0 & 0 & 0,0 & 1 & 0 & 0 & 0 & 0 & 0 & 2 \\
\hline & & & $\%$ & 50,0 & 0,0 & 0,0 & 0,0 & 0 & 50,0 & 0,0 & 0,0 & 0,0 & 0,0 & 0,0 & 0,6 \\
\hline & & Göğüs & $\mathrm{n}$ & 2 & 0 & 4 & 0 & 0 & 0 & 0 & 0 & 0 & 0 & 0 & 6 \\
\hline & & & $\%$ & 33,3 & 0,0 & 66,7 & 0,0 & 0,0 & 0,0 & 0,0 & 0,0 & 0,0 & 0,0 & 0,0 & 1,9 \\
\hline & & Baş & $\mathrm{n}$ & 0 & 0 & 0 & 0 & 0 & 0 & 0 & 2 & 0 & 0 & 1 & 3 \\
\hline & & & $\%$ & 0,0 & 0,0 & 0,0 & 0,0 & 0,0 & 0,0 & 0,0 & 66,7 & 0,0 & 0,0 & 33,3 & 1,0 \\
\hline & & Diğer & $\mathrm{n}$ & 1 & 0 & 1 & 0 & 0 & 0 & 0 & 0 & 0 & 0 & 2 & 4 \\
\hline & & & $\%$ & 25,0 & 0,0 & 25,0 & 0,0 & 0,0 & 0,0 & 0,0 & 0,0 & 0,0 & 0,0 & 50,0 & 1,3 \\
\hline & Toplam & & $\mathrm{n}$ & 70 & 101 & 39 & 39 & 7 & 20 & 14 & 6 & 2 & 6 & 5 & 309 \\
\hline & & & $\%$ & 22,7 & 32,7 & 12,6 & 12,6 & 2,3 & 6,5 & 4,5 & 1,9 & 0,6 & 1,9 & 1,6 & 100,0 \\
\hline \multirow{22}{*}{ 总 } & \multirow{20}{*}{ 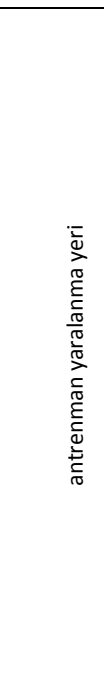 } & Ayak-ayak & $n$ & 9 & 75 & 5 & 0 & 2 & 0 & 1 & 0 & 0 & 0 & 1 & 93 \\
\hline & & bileği & $\%$ & 9,7 & 80,6 & 5,4 & 0,0 & 2,2 & 0,0 & 1,1 & 0,0 & 0,0 & 0,0 & 1,1 & 30,8 \\
\hline & & Diz & $n$ & 11 & 2 & 2 & 0 & 4 & 0 & 18 & 0 & 0 & 0 & 0 & 37 \\
\hline & & & $\%$ & 29,7 & 5,4 & 5,4 & 0,0 & 10,8 & 0,0 & 48,6 & 0,0 & 0,0 & 0,0 & 0,0 & 12,3 \\
\hline & & El-el bileği & $n$ & 22 & 7 & 20 & 14 & 0 & 1 & 0 & 0 & 0 & 0 & 7 & 71 \\
\hline & & & $\%$ & 31,0 & 9,9 & 28,2 & 19,7 & 0,0 & 1,4 & 0,0 & 0,0 & 0,0 & 0,0 & 9,9 & 23,5 \\
\hline & & Dirsek & $n$ & 3 & 3 & 8 & 7 & 0 & 0 & 0 & 1 & 0 & 0 & 0 & 22 \\
\hline & & & $\%$ & 13,6 & 13,6 & 36,4 & 31,8 & 0,0 & 0,0 & 0,0 & 4,5 & 0,0 & 0,0 & 0,0 & 7,3 \\
\hline & & Omuz & $n$ & 12 & 1 & 3 & 10 & 0 & 2 & 7 & 0 & 1 & 0 & 0 & 36 \\
\hline & & & $\%$ & 33,3 & 2,8 & 8,3 & 0 & 0 & 5,6 & 19,4 & 0,0 & 2,8 & 0,0 & 0,0 & 11,9 \\
\hline & & Baldır-uyluk & $n$ & 4 & 0 & 0 & 0,0 & 0,0 & 10 & 3 & 0 & 0 & 0 & 0 & 17 \\
\hline & & & $\%$ & 23,5 & 0,0 & 0,0 & 0 & 0 & 58,8 & 17,6 & 0,0 & 0,0 & 0,0 & 0,0 & 5,6 \\
\hline & & Bel & $n$ & 6 & 0 & 0 & 0,0 & 0,0 & 0 & 0 & 0 & 0 & 7 & 0 & 13 \\
\hline & & & $\%$ & 46,2 & 0,0 & 0,0 & 0 & 0 & 0,0 & 0,0 & 0,0 & 0,0 & 53,8 & 0,0 & 4,3 \\
\hline & & Kalça & $n$ & 0 & 0 & 0 & 0,0 & 0,0 & 0 & 1 & 0 & 0 & 0 & 0 & 1 \\
\hline & & & $\%$ & 0,0 & 0,0 & 0,0 & 0 & 0 & 0,0 & 100,0 & 0,0 & 0,0 & 0,0 & 0,0 & 0,3 \\
\hline & & Göğüs & $n$ & 4 & 0 & 1 & 0,0 & 0,0 & 0 & 0 & 0 & 0 & 0 & 1 & 6 \\
\hline & & & $\%$ & 66,7 & 0,0 & 16,7 & 0 & 0 & 0,0 & 0,0 & 0,0 & 0,0 & 0,0 & 16,7 & 2,0 \\
\hline & & Baş & $n$ & 0 & 0 & 3 & 0,0 & 0,0 & 0 & 1 & 0 & 0 & 0 & 2 & 6 \\
\hline & & & $\%$ & 0,0 & 0,0 & 50,0 & 0 & 0 & 0,0 & 16,7 & 0,0 & 0,0 & 0,0 & 33,3 & 2,0 \\
\hline & \multirow[t]{2}{*}{ Toplam } & & $n$ & 71 & 88 & 42 & 31 & 6 & 13 & 31 & 1 & 1 & 7 & 11 & 302 \\
\hline & & & $\%$ & 23,5 & 29,1 & 13,9 & 10,3 & 2,0 & 4,3 & 10,3 & 0,3 & 0,3 & 2,3 & 3,6 & 100,0 \\
\hline
\end{tabular}


Tablo 12 (Devam). Judo ve Güreş Yapan Sporcuların Antrenmanda Geçirdikleri Yaralanmaların Türü ve Yaralanma Yeri Dağılımları

\begin{tabular}{|c|c|c|c|c|c|c|c|c|c|c|c|c|c|c|c|}
\hline \multirow[b]{2}{*}{ Branş } & & & & \multicolumn{11}{|c|}{ Antrenmanda geçirilen yaralanma } & \multirow[b]{2}{*}{ Toplam } \\
\hline & & & & $\begin{array}{l}\text { Kondüzyon- } \\
\text { laserasyon }\end{array}$ & Burkulma & Kırık & Çıkık & Kopma & Çekme & Yırtık & Tendinit & Sıkışma & $\begin{array}{c}\text { Fitık- } \\
\text { paraverteb } \\
\text { ral spazm }\end{array}$ & Diğer & \\
\hline \multirow{24}{*}{$\begin{array}{l}\bar{\pi} \\
\stackrel{5}{0}\end{array}$} & \multirow{20}{*}{ 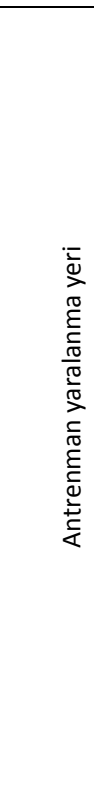 } & \multirow{2}{*}{$\begin{array}{l}\text { Ayak-ayak } \\
\text { bileği }\end{array}$} & $\mathrm{n}$ & 25 & 163 & 18 & 2 & 8 & 0 & 1 & 0 & 0 & 0 & 1 & 218 \\
\hline & & & $\%$ & 11,5 & 74,8 & 8,3 & 0,9 & 3,7 & 0,0 & 0,5 & 0,0 & 0,0 & 0,0 & 0,5 & 35,7 \\
\hline & & \multirow[t]{2}{*}{ Diz } & $\mathrm{n}$ & 16 & 4 & 2 & 3 & 5 & 0 & 28 & 0 & 0 & 0 & 0 & 58 \\
\hline & & & $\%$ & 27,6 & 6,9 & 3,4 & 5,2 & 8,6 & 0,0 & 48,3 & 0,0 & 0,0 & 0,0 & 0,0 & 9,5 \\
\hline & & \multirow[t]{2}{*}{ El-el bileği } & $\mathrm{n}$ & 28 & 17 & 34 & 31 & 0 & 1 & 0 & 4 & 0 & 2 & 9 & 126 \\
\hline & & & $\%$ & 22,2 & 13,5 & 27,0 & 24,6 & 0,0 & 0,8 & 0,0 & 3,2 & 0,0 & 1,6 & 7,1 & 20,6 \\
\hline & & \multirow[t]{2}{*}{ Dirsek } & $\mathrm{n}$ & 7 & 4 & 15 & 11 & 0 & 0 & 0 & 1 & 0 & 0 & 0 & 38 \\
\hline & & & $\%$ & 18,4 & 10,5 & 39,5 & 28,9 & 0,0 & 0,0 & 0,0 & 2,6 & 0,0 & 0,0 & 0,0 & 6,2 \\
\hline & & \multirow[t]{2}{*}{ Omuz } & $\mathrm{n}$ & 37 & 1 & 3 & 23 & 0 & 2 & 11 & 0 & 3 & 0 & 0 & 80 \\
\hline & & & $\%$ & 46,3 & 1,3 & 3,8 & 28,8 & 0,0 & 2,5 & 13,8 & 0,0 & 3,8 & 0,0 & 0,0 & 13,1 \\
\hline & & \multirow{2}{*}{$\begin{array}{l}\text { Baldır- } \\
\text { uyluk }\end{array}$} & $\mathrm{n}$ & 11 & 0 & 0 & 0 & 0 & 29 & 3 & 0 & 0 & 0 & 0 & 43 \\
\hline & & & $\%$ & 25,6 & 0,0 & 0,0 & 0,0 & 0,0 & 67,4 & 7,0 & 0,0 & 0,0 & 0,0 & 0,0 & 7,0 \\
\hline & & \multirow[t]{2}{*}{ Bel } & $\mathrm{n}$ & 9 & 0 & 0 & 0 & 0 & 0 & 0 & 0 & 0 & 11 & 0 & 20 \\
\hline & & & $\%$ & 45,0 & 0,0 & 0,0 & 0,0 & 0,0 & 0,0 & 0,0 & 0,0 & 0,0 & 55,0 & 0,0 & 3,3 \\
\hline & & \multirow[t]{2}{*}{ Kalça } & $n$ & 1 & 0 & 0 & 0 & 0 & 1 & 1 & 0 & 0 & 0 & 0 & 3 \\
\hline & & & $\%$ & 33,3 & 0,0 & 0,0 & 0,0 & 0,0 & 33,3 & 33,3 & 0,0 & 0,0 & 0,0 & 0,0 & 0,5 \\
\hline & & \multirow[t]{2}{*}{ Göğüs } & $\mathrm{n}$ & 6 & 0 & 5 & 0 & 0 & 0 & 0 & 0 & 0 & 0 & 1 & 12 \\
\hline & & & $\%$ & 50,0 & 0,0 & 41,7 & 0,0 & 0,0 & 0,0 & 0,0 & 0,0 & 0,0 & 0,0 & 8,3 & 2,0 \\
\hline & & \multirow{2}{*}{ Baş } & $n$ & 0 & 0 & 3 & 0 & 0 & 0 & 1 & 2 & 0 & 0 & 3 & 9 \\
\hline & & & $\%$ & 0,0 & 0,0 & 33,3 & 0,0 & 0,0 & 0,0 & 11,1 & 22,2 & 0,0 & 0,0 & 33,3 & 1,5 \\
\hline & & \multirow[t]{2}{*}{ Diğer } & $\mathrm{n}$ & 1 & 0 & 1 & 0 & 0 & 0 & 0 & 0 & 0 & 0 & 2 & 4 \\
\hline & & & $\%$ & 25,0 & 0,0 & 25,0 & 0,0 & 0,0 & 0,0 & 0,0 & 0,0 & 0,0 & 0,0 & 50,0 & 0,7 \\
\hline & \multirow[t]{2}{*}{ Toplam } & & $n$ & 141 & 189 & 81 & 70 & 13 & 33 & 45 & 7 & 3 & 13 & 16 & 611 \\
\hline & & & $\%$ & 23,1 & 30,9 & 13,3 & 11,5 & 2,1 & 5,4 & 7,4 & 1,1 & 0,5 & 2,1 & 2,6 & 100,0 \\
\hline
\end{tabular}


Banu KABAK Muharrem KARANFiLCI Nuran KARAKUYU

Tüm sporcuların \% 30,9'un ( $n=189$ ) antrenman sırasında geçirdiği spor yaralanması burkulmadır. Tüm sporcuların \% 35,7'in $(n=218)$ antrenman sırasında geçirdiği sakatlığının yeri ayak-ayak bileğinde görülmüştür. Judo yapan sporcuların antrenman sırasında en sık sırasıyla, \%32,7'sinde $(n=101)$ burkulma, \%22,7'sinden $(n=70)$ kontüzyon-laserasyon, \%12,6'sında (n=39) kırık ve aynı oranda çıkık görülmüştür. Judo yapan sporcuların antrenman sırasında geçirdiği en sık yaralanmanın yerleri sırasıyla \% 40,5'si ( $n=125)$ ayak-ayak bileği, \%17,8'si $(n=55)$ el-el bileği ve $\% 14,2$ 'si $(n=44)$ omuzdur. Antrenman sırasında güreş yapan sporcuların $\% 29,1^{\prime}$ inde $(n=88)$ burkulma, \%23,5'inde $(n=71)$ kontüzyon-laserasyon, \%13,9'unda ( $\left.n=42\right)$ kırık görülmüştür. Antrenman sırasında güreşçilerin geçirdiği en sık spor yaralanma yerleri sırasıyla \% 30,8'in ( $n=93$ ) ayak-ayak bileği, \%23,5'nin ( $n=71)$ el-el bileği ve \%12,3'ün ( $n=37)$ dizdir(Tablo.12).

\section{TARTIŞMA}

Çalışmada judo yapan sporcular müsabaka sırasında en sık burkulma ve kontüzyonlaserasyon yaralanması geçirirken, güreş branşında kırık ve kontüzyon-laserasyon yaralanmaları olduğu tespit edilmiştir. Hem güreşçilerde hem de judo yapanlarda ayak-ayak bileği, el-el bileği ve omuz bölgelerindeki yaralanmaların daha fazla olduğu görülmüştür. Ayrıca, göğüs ve bel yaralanmaları güreş branşında daha fazla görülürken diz yaralanmaları ise judo branşında daha fazla ortaya çıkmıştır.

Çalışmada her iki spor branşında da antrenmanda sırasında benzer yaralanmaların benzer oranlarda ve benzer vücut bölgelerinde ortaya çıktığı görülmektedir. Her iki spor branşında da ayak ve ayak bileği, el ve el bileği, dirsek ve omuz yaralanmaları ön plana çıkmıştır. Farklı olarak diz, bel ve baş yaralanmaları güreş branşında daha fazla görülmüştür.

Incelenen literatür çalışmalarında judo spor dalında \%28 oranında diz, \%22 oranında omuz, \%30 oranında el ve parmaklarda yaralanmalarının sıklıkla görüldüğü tespit edilmiştir [13-16]. Çalışmalar özellikle müsabaka sırasında kavramayla oluşan parmak yaralanmalarının fazlalığına dikkat çekmektedir [19]. Birçok çalışmada atma ve atılmanın sonucunda judocularda omuz ve diz yaralanmalarının daha sık görüldüğünü savunulmaktadır [20-22].

Pocecco ve ark. 2008 ve 2012 Olimpiyat Oyunları sırasında elektronik veri tabanlarından elde ettikleri sonuçlara göre fırlatma anında judoda en sık yaralanmalar diz, omuz ve 
parmaklarda burkulma $(59,8 \%)$, strain $(33,8 \%)$ ve kontüzyon $(56 \%)$ olduğunu bildirmişlerdir [11]. Noh ve ark'ın (2015) yaptığı bir çalışmada judo, güreş, sumo güreşi, boks, tekvando ve kendo yapan sporcuların yaralanma tipi ve bölgeleri araştırılmıştır. Buna göre; Judo yapan sporcularda en sık görülen yaralanmanın sırasıyla ligament rüptürü $(\% 58,7)$, kontüzyon ve kırık (\%50) ve burkulma $(\% 47,8)$, güreş yapan sporcularda ise burkulma $(\% 91,7)$, kontüzyon $(\% 66,7)$, kırık $(\% 33,3)$ ligament $(\% 33,3)$ ve kas $(\% 33,3)$ rüptürü görüldüğünü ve yaralanma bölgesinin ise en sık judocularda alt ekstremite $(\% 28,9)$ ve boyunda $(\% 21,1)$ görülürken güreşçilerde de alt ekstremite $(\% 68,8)$ ve boyunda $(\% 30,8)$ olduğunu bildirmişlerdir [23].

Judo yapan 5-17 yaş grubu sporcularda en fazla yaralanmanın \%19 oranında omuz ve üst kol, \%16 oranında ayak ve ayak bileği ile \%15 oranında dirsek ve el bileğinde ortaya çıktığı belirtilmiştir [24]. Bu çalışmada da benzer şekilde en sık spor yaralanması geçiren yaş grubunun 13-15 ile 16-18 olduğu saptanmıştır. Judo yaralanmalarının türleri incelendiğinde, omuzda çıkık, parmaklarda yanlış kavramadan kaynaklanan kırık ve çıkık, ayak bileği burkulmaları, kontüzyonlar ve çekmeler en yaygın yaralanmalar olarak gösterilmektedir $[25,26]$. Buna ek olarak dizde ön çapraz bağ yaralanmaları ve dirsekte bağ yaralanmaları da literatüre geçmiş yaralanmalar arasında gösterilmektedir $[27,28]$. Yapılan çalışmada bulunan yaralanma türlerinin oranları da literatürle uyumludur.

Güreş yaralanmaları incelendiğinde; üst ekstremitelere binen aşırı kuvvetler ve olağan dışı pozisyonlar nedeniyle omuz, kol ve parmak yaralanmalarının sıklığı güreş sporunda dikkat çekmektedir [29,30]. Yapılan bir prospektif çalışmada toplam güreş yaralanmaları içerisinde omuz yaralanmalarının \% 24 'lük orana ulaştığı tespit edilmiştir [31]. Dirsek ve omuz yaralanmaları daha az sıklıkla, ancak sürekli ve daha şiddetli olarak ortaya çıkmaktadır. Prospektif ve retrospektif çalışmalarda dirsek yaralanmaları, tüm güreş yaralanmalarının \% 1,07,9 oluşturmaktadır [32,33]. En yaygın el yaralanmaları metakarpofalangeal burkulma, proksimal interfalangeal burkulma ve başparmak metakarpofalangial, unlar kollateral ligament burkulmaları olarak gösterilmektedir. Prospektif çalışmalarda, ayak bileği yaralanmalarının tüm güreş yaralanmaları içerisinde \% 3,2 - 9,7 arasında değiştiğini göstermektedir. Güreş spor dalında görülen başlıca yaralanma türleri ise yine prospektif çalışmalardan elde edilen sonuçlara göre kırıklar, ayak bileği eksternal rotasyon burkulmaları, kontüzyon ve laserasyonlar, kas yırtıkları olarak ortaya çıkmaktadır [34]. Bu literatür sonuçları ile yapılan çalışma benzerlik göstermektedir. Myers ve ark, yedi yıllık bir takip sonrası güreş ile ilgili yaralanmaların 12-17 
yaş grubunda 7-11 yaş grubuna göre 5 kat daha fazla olduğunu rapor etmişlerdir. Her iki grupta da en sık burkulma ve bunu kırık ve kontüzyon izlediğini ve en sık bilek/el/parmaklarda daha sonra baş/boyun ve omuzda spor yaralanması olduğunu bildirmişlerdir [5].

Wojciech ve ark, yaptığı bir çalışmada boks, judo, karate, tekvando, kickboks gibi farklı dövüş sporlarında spor sakatlıklarını ve sıklığını araştırmışlar. Judo yapanların \% 28'sinin diz yaralanması, \%24'nün kırık geçirdiklerini bildirmişlerdir. Ayrıca çalışmaya alınan katılımcıların \% 59 yarışma anında, \% 25'i antrenman sırasında yaralanma geçirdiklerini belirtmişlerdir [35].

Çalışmamızda hem antrenman hem de müsabaka sırasında yaralanma geçiren judo ve güreşçilerin büyük çoğunluğu 1 aydan daha az bir süre sportif aktiviteler yapmamışlardır. Açak'ın yaptığı bir çalışmada güreş yapan sporcuların \% 50'si 1-3 hafta sportif faaliyetlerden uzak dururken sporcuların \% 15’i daha uzun süre uzak kaldığını bildirmiştir [4].

Yapılan çalışma sonucunda elde edilen bulgulardan güreş ve judo spor dallarında antrenmanda ve müsabakada meydana gelen yaralanmaların benzer yaralanmalar olduğu ve benzer vücut bölgelerinde görüldüğü tespit edilmiştir. Bu spor dallarının yapılışındaki temel özelliklerin benzer yaralanmalara sebebiyet verdiği düşünülmekle birlikte bu konuyla ilgili daha kapsamlı çalışmalara intiyaç duyulmaktadır.

\section{KAYNAKLAR}

1. Türker T, Necmettin K, Hakan I, Ali Osman Y, Tayfun K, Cengizhan A, Selim K. Tıp fakültesi öğrencilerinin spor yapma alışkanlıkları ve spor yaralanmalarının değerlendirilmesi. Gülhane Tıp Derg. 2011; 53: 94-98.

2. Ergen E, Güner R, Zergeroğlu MA, Ulkar B, Kunduracıoğlu B. Sporcu Sağlığı ve Spor Yaralanmaları. Ankara, Nobel Yayın Dağıtım, 2003.

3. Sakallı FMH. Sporda Sporcuların Yaralanması ve Risk Faktörleri. Fırat Sağlık Hizmetleri Dergisi, 2008, 3(7): 144-154.

4. Açak, M. The Importance of Motor Tests in Reducing the Injury of Children Who Are New to Wrestling. International Journal of Wrestling Science, 5.1 (2015): 47-51.

5. Myers RJ, Linakis SW, Mello MJ, Linakis JG. Competitive wrestling related injuries in school aged athletes in U.S Emergency Departments. West J Emerg Med, 2010 Dec;11(5):442-449.

6. Baker BE, Peckham AC, Pupparo F, Sanborn JC. Review of meniscal injury and associated sports. Am J Sports Med, 1985; 13 (1):1-4.

7. Jarret GJ, Orwin JF, Dick RW. Injuries in collegiate wrestling. Am J Sports Med, 1998; 26(5):674-80.

8. Türkiye Judo Federasyonu. Erişim http/www.judo.gov.tr.

9. Pocecco E, Faulhaber M, Franchini E, Burtscher M. Aerobic power in child, cadet and senior judo athletes. Biol Sport, 2012;29:217-22.

10. Pocecco E, Gatterer H, Ruedl G, Burtscher M. Specific exercise testing in judo athletes. Arch Budo, 2012; 8: 133-9 
11. Pocecco E, Ruedl G, Stankovic N, Sterkowicz S, Del Vecchio FB, Gutiérrez-García C,et al. Injuries in judo: a systematic literature review including suggestions for prevention. $\mathrm{Br} J$ Sports Med, 2013 Dec;47(18):1139-43.

12. Gutierrez García C, Perez Gutierrez M, Svinth J. Judo. In: Green T, Svinth J. Eds. Martial arts of the world. An encyclopedia of history and innovation. California: ABC-CLIO , Santa Barbara, 2010;1:1 27-32.

13. Green CM, Petrou MJ, Fogarty-Hover ML, Koop M, Wolf M, Miarca B, et al. Injuries in Judo. Br J Sports Med. 2013;47(18):1139-1143.

14. Pierantozzi E, Muroni R. Judo high level competitions injuries. Medit J Musc Surv, 2009;17:26-9.

15. Frey A, Müller W. Heberden arthroses in judo athletes. Schweiz Med Wochenschr, 1984;114:40 -7.

16. Strasser $P$, Hauser $M$, Häuselmann HJ. Traumatic finger polyarthrosis in judo athletes: a follow-up study. Z. Rheumatol, 1997;56:342 -50.

17. Uchida R. Deaths during the judo classes and activities conducted under thesupervision of schools in Japan; from 1983 to 2009 all cases listed and analyzed. Aichi University of Education. http://judojiko.net/eng/wp-content/upload s/2011/01/en_judo_data110110. pdf (accessed 31 April 2015).

18. Kamitani T, Nimura Y, Nagahiro S, Miyazaki S, Tomatsu T. Catastrophic head and neck injuries in judo players in Japan from 2003 to 2010. Am J Sports Med, 2013;41:1915-21.

19. Miarka B, Panissa V, Julio UF. A comparison of time-motion performance between age groups in judo matches. J Sports Sci, 2012;30:899-905.

20. Souza M, Monteiro H, Del Vecchio F. Referring to judo's sports injuries in Sao Paulo State Championship. Sci Sports, 2006;21: $280-4$.

21. Barsottini D, Guimarães AE, de Morais PR. Relaçaoentretecnicas e lesoes em praticantes de judo. Rev Bras Med Esporte, 2006;12:56-60.

22. Cynarski WJ, Kudlacz M. Injuries in martialartsand combat sports-a comparative study. Arch Budo, 2008;4:91 -7.

23. Noh JW, Park BS, Kim MY, Lee LK, Yang SM, Lee WD et al. Analysis of combat sports players injuries according to playing style for sports physiotherapy research. J Phys Ther Sci, 2015 Aug;27(8):242530

24. Yard EE, Knox CL, Smith GA. Pediatric martialarts injuries presenting to emergency departments, United States 1990-2003. J Sci Med Sport, 2007;10:219-26.

25. Scoggin JF, Brusovanik G, Pi M. Assessment of injuries sustained in mixed martialarts competition. Am J Orthop, 2010;39:247 -51.

26. Barrault D, Brondani JC, Rousseau D. Médecine du Judo. Paris, France: Masson, 1991:113 - 223.

27. den Bekerom MPJ, Kerkhoffs GM, Mc Collum GA. Management of acute lateral ankle ligament injury in the athlete. Knee Surg Sports Traumatol Arthrosc, 2013;21:1390-5.

28. Egoumenides M. Traumatologiedes Sports de Combat . Paris, France: Sauramps Medical, 1989:2635.

29. Lorish TR, Rizzo TD Jr, Ilstrup DM, Scott SG. Injuries in adolescent and preadolescent boys at two large wrestling tournaments. Am J Sports Med, 1992;20:199-202.

30. Requa R, Garrick J. Injuries in inter scholastic wrestling. Physician Sportsmed, 1981;9:44-51.

31. Pasque $C B$, Hewett TE. A prospective study of highschool wrestling injuries. Am J Sports Med, 2000;28:509-515.

32. Weiss C, Sawers R. Avulsion fracture of the olecranon process. Physician Sports med, 1990;18: 110116.

33. Banas MP, Lewis RA. Non union of an olecranon epiphyseal plate stres fracture in an adolescent. Orthopedics, 1995;18:1111-1112.

34. Hewetta TE, Pasquec C, Heyla R, Wrobled R. Wrestling Injuries, Caine DJ, Maffulli N (eds): Epidemiology of Pediatric Sports Injuries. Individual Sports. MedSport Sci, 2005; 48:152-178.

35. Wojciech J. Cynarski, Marcin Kudłacz Injuries in martial arts and combat sports- a comparative study Archives of Budo, 2008; 4: 91-97 